\title{
The impact of big data and business analytics on supply chain management
}

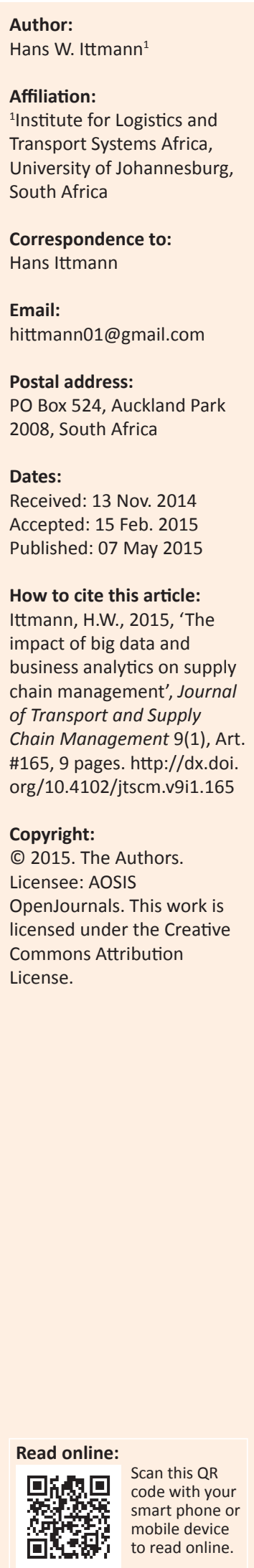

Background: Change is inevitable and as supply chain managers prepare for the future they face many challenges. Two major trends over the last few years are the growing importance of 'big data' and analysing these data though 'analytics'. The data contain much value and companies need to capitalise on the variety of data sources by in-depth and proper analysis through the use of 'big data' analytics.

Objective: This article endeavours to highlight the evolving nature of the supply chain management (SCM) environment, to identify how the two major trends ('big data' and analytics) will impact SCM in future, to show the benefits that can be derived if these trends are embraced and to make recommendations to supply chain managers.

Method: The importance of extracting value from the huge amounts of data available in the SCM area is stated. 'Big data' and analytics are defined and the impact of these in various SCM applications clearly illustrated.

Results: It is shown, through examples, how the SCM area can be impacted by these new trends and developments. In these examples 'big data' analytics have already been embraced, used and implemented successfully. Big data is a reality and using analytics to extract value from the data has the potential to make a huge impact.

Conclusion: It is strongly recommended that supply chain managers take note of these two trends, since better use of 'big data' analytics can ensure that they keep abreast with developments and changes which can assist in enhancing business competitiveness.

\section{Introduction}

The logistics and supply chain management (SCM) field is a 'living, changing thing' (Eccles 1954:15) and very dynamic. This has been very evident over the last 50 years. The field has advanced from physical distribution, as it was defined in the early 1960s, to what is now generally considered a function that encompasses the entire organisation (Stock 2013:23). Where the focus was on striving towards 'strategies for reducing cost and improving service' (Christopher 1998), the emphasis has shifted to ensuring a cost-effective, reliable and predictable service.

Many developments, including enterprise resource planning, materials requirements planning, efficient consumer response, customer relationship management, vendor management inventory, transportation management systems, just-in-time, warehouse management systems, total quality control, collaborative planning, forecasting, and replenishment, plus various other methodologies have contributed to this advancement (Stock 2013:23). The role of information technology (IT) and computers was critical in these developments, which were stimulated enormously by the ever-improving technology and increase in computer power.

In addition, various external events and factors such as natural disasters have focused the attention of supply chain professionals on other aspects, inter alia uncertainty and risk management in the supply chain. Humanitarian and disaster management was an outflow of these occurrences (Tomasini \& Van Wassenhove 2009). Sustainable development and environmental concerns were instrumental in the development of green logistics (McKinnon et al. 2010).

Some of these developments benefitted supply chains in a positive way, whilst others have placed additional burdens on the supply chain. Today the field is certainly very rich and mature, but logistics and supply chain professionals know and realise that in a changing environment there will always be different circumstances, new issues and new challenges to be addressed.

One of the major trends over the last number of years that affects companies in every sector of the economy is the realisation for the need to move towards more accurate, data-driven insight to 
achieve effective decision making. With increased and more sophisticated developments in IT, more powerful computers and the abundance of personal electronic devices, the world has moved into the 'big data' era. Data now have the power to help businesses succeed - but this can only be achieved through appropriate and proper analysis, through the use of what is called 'analytics' of these big volumes of data. The impact or potential impact of this has been (or could be) widespread in many different sectors, and certainly also the SCM and logistics area (Davenport \& Harris 2007:9). The aim of this article is to highlight and discuss various concepts around these developments, show how the SCM area can be impacted, and illustrate through examples how they have already been embraced, used and implemented successfully.

This article therefore endeavours to expose supply chain managers to these changes and to highlight, define and discuss the various concepts and trends around 'big data' and analytics. The aim is to show how SCM can be impacted by these developments, using a number of examples, and how companies have benefitted from these opportunities by increasing their competitiveness.

The article is divided into a number of sections. A brief literature review is provided in the next section, illustrating growing recognition of the importance of extracting value through analysing big data in the SCM environment. In the third section the emphasis is on big data, what this entails and whether this is indeed an important topic that needs to be taken seriously by supply chain executives. Analytics or business analytics, the term used to describe the analysis of data, is the focus of the fourth section. The objective is to define what is understood by this term and how this, together with big data, can be used to enhance decision making and ultimately the competitiveness of companies. There still are those that are sceptical about whether this is indeed something new (Ittmann 2013). Supply chain analytics, or analytics specific to supply chains, is the topic of the fifth section. Section six is devoted to the potential impact of big data and analytics on SCM. Specific areas of SCM that could be affected, and in what way, are highlighted whilst a number of case studies with actual examples are discussed. Finally, some concluding remarks and recommendations are provided.

\section{Literature review}

Stock (2013:24), having considered past developments in SCM, looks ahead and identifies a number of the 'most notable' developments that will shape the future of the profession. Included amongst those identified are continuous upgrades in technology, and the growing importance of 'big data' and data analytics in SCM. Technological developments such as more sophisticated software, wireless systems, smart phones and other devices are mentioned as all getting seemingly smaller, cheaper and more mobile - examples that already have and will continue to impact SCM. Not only will this technology allow decision makers to make decisions faster, but it will allow large data sets to be analysed quicker to determine the best course of action for specific circumstances. Stock (2013:24) quotes an IBM report (Coles et al. 2006:2) which indicated that by 2010 knowledge will double every 11 hours. The way to keep up with this increasing variety of data sources is through better use of 'big data' analytics (data analysis). Companies that are using business analytics more extensively believe they have improved their performance. Finally, Stock (2013:25) notes that the potential uses of big data analytics are myriad.

In a survey conducted in 2013 by Deloitte and MHI (2014), supply chain executives were questioned about 'innovations that drive supply chains'. The aim was to obtain the views of executives on emerging supply chain trends that could dramatically impact supply chains of the future. The two top strategic priorities for supply chain executives that emerged from the survey were supply chain analytics and multichannel fulfilment (Deloitte \& MHI 2014:2). Elaborating on supply chain analytics, the survey indicated that these are:

tools and techniques that harness data from a wide range of internal and external sources to produce breakthrough insights that can help supply chains reduce costs and risk whilst improving operational agility and service quality. (p. 2)

However, according to the executives surveyed the supply chain function was behind other functions in capitalising on the power of analytics.

Cooke (2013:11) mentions the increased use of 'big data' analytics as one of the three trends in SCM to watch. Analysing enormous amounts of information from disparate databases provides supply chain managers with the ability to improve supply chain performance. A number of examples are mentioned where this type of analysis can impact performance in the supply chain.

In an editorial Waller and Fawcett (2013:77) indicate that 'big data' is not just a buzzword but that proper data analysis together with 'the growing combination of resources, tools and applications has deep implications in the field of SCM which not only presents an opportunity but also a huge challenge'. Their emphasis is on research that is required where SCM interacts with data science, predictive analytics and big data. In addition, they also strongly emphasise the importance of skills development in this new developing area, with specific emphasis on big data. All of this has the potential to revolutionise supply chain dynamics.

The Council for Supply Chain Management Consultants considered the topic of 'big data' in SCM to be so important that a research project was commissioned on it. An initial report titled Big data (Richey et al. 2014) was published recently, which is based on in-depth interviews to obtain the inputs of supply chain managers on 'What is big data?'; 'What are the obstacles to using big data?' and 'What are the opportunities of using big data?' The ultimate aim of this study was to uncover best practices in using big data for superior SCM performance. From the initial interviews in this 
study it is clear that there is currently very little agreement amongst those interviewed on what purpose big data serves and what it means for the future of SCM.

There are various environments where big data with the appropriate use of analytics has proved to be of immense value. One of the first and much published examples is captured in Lewis (2003), where it is shown how an underrated baseball team's use of analytical and evidence-based data on player performance changed it into a very competitive team. The victories in the United States presidential elections in 2008 and 2012 by President Baraka Obama are accredited to the wide use of 'big data' analytics during both election campaigns (Samuelson 2009, 2013). A further recent example in the political sphere is discussed in Samuelson (2014).

Multiple big data applications in the marketing environment are showing tremendous potential in driving marketing opportunities and impacting the customer management domain (Svilar, Chakraborty \& Kanioura 2013:22-25). The areas of application are growing as well as the number of books devoted to this topic. Books published over the last few years include the following: Baesens (2014), Dietrich, Plachy and Norton (2014), Sathi (2012) and Siegel (2013). Watson et al. (2012) is specifically devoted to supply chain network design using big data and analytics.

From the literature review there is clearly an anticipation that the critically important organisational function of SCM will need to evolve and adapt to 'big data' analytics. It has been shown how a range of different areas has already benefitted immensely from the use of 'big data' analytics. Currently the world finds itself within the era of 'big data', and many have recognised the value that can be attained from the analysis of data. There is no doubt of the potential captured in these trends, and as a number of supply chain professionals have suggested, there is a need within the supply chain fraternity to embrace these developments to continually improve the performance and competitiveness of supply chains. Richey et al. (2014) indicate an element of conservatism and scepticism amongst supply chain managers around these developments. The objective of this article is therefore to expose those in the industry to what 'big data' and analytics are and, through a few current successful case studies, to accelerate organisational adaptation to achieve 'big impact through big data' (Court 2015).

\section{Big data}

McAfee and Brynjolfsson (2012) call big data a management revolution that is taking place. They use an example of retailing which is self-explanatory to illustrate this:

Booksellers in physical stores could always track which books sold and which did not. If they had a loyalty program, they could tie some of those purchases to individual customers. And that was about it. Once shopping moved online, though, the understanding of customers increased dramatically. Online retailers could track not only what customers bought, but also what else they looked at; how they navigated through the site; how much they were influenced by promotions, reviews, and page layouts; and similarities across individuals and groups. Before long, they developed algorithms to predict what books individual customers would like to read next - algorithms that performed better every time the customer responded to or ignored a recommendation. Traditional retailers simply couldn't access this kind of information, let alone act on it in a timely manner. It's no wonder that Amazon has put so many brick-andmortar bookstores out of business. (p. 61)

Further real examples where the quantity of data accumulated increase almost by the minute are the following (SAS 2012):

- Wal-Mart handles more than a million customer transactions each hour and imports those into databases estimated to contain more than 2.5 petabytes of data.

- Radio frequency identification systems used by retailers and others can generate from 100 to 1000 times the data of conventional barcode systems.

- Each day Facebook handles more than 250 million photo uploads and the interactions of 800 million active users, with more than 900 million objects (pages, groups, etc.).

- More than 5 billion people are calling, texting, tweeting and browsing on mobile phones worldwide.

All of the above examples show that huge amounts of data are collected and generated by everything around us all the time. The internet, every digital process, mobile phones, social media, loyalty card schemes, sensors, etc., are examples of how data are generated and accumulated. Some of the examples mentioned also show that this explosion of data is happening within the realm of SCM and logistics.

The big data drive seeks to gain intelligence from data and translate that into an advantage for business. Big data is, however, distinguished by four dimensions (Dietrich et al. 2014; Sathi 2014; SAS 2012), namely:

- Volume - the increasing size of data and data bases. These sizes can range from terabytes to petabytes of data.

- Variety - the different forms of data: structured and unstructured, text, sound, video, multimedia, etc.

- Velocity - the speed at which data are available as well as the throughput of the data. The analysis of streaming data is also called latency, namely how fast data can be analysed. This is achieved more and more by embedding the data analysis in the business processes.

- Veracity - the data quality, correctness and accuracy, which determines both the credibility of the data as well as the suitability. Managing the reliability of data becomes crucial.

Big data is changing the way people work within organisations, Davenport (2006) gives numerous examples. It is not only creating a culture where business and IT leaders must join forces to realise value from all data, but they are also encouraged to work together across various functional areas (Davenport \& Harris 2007). Insights from big data can enable those in organisations to make better decisions. In addition it can assist, inter alia, in deepening customer 
engagement, optimising operations, preventing threats and fraud, managing inventory optimally and capitalising on new sources of revenue. This increasing demand for improved insights requires a fundamentally new approach. An approach to extract meaningful value from big data requires optimal processing power as well as capabilities to analyse the data (analytics) as well as appropriate skills (Davenport, Harris \& Morison 2010; Davenport, Barth \& Bean 2012). For the SCM and logistics fraternity this confirms the view of Stock (2013:24) that the developments around big data are one of the 'most notable' trends in the area.

It is clear from the above that value resides in big data, and the insights derived from the data can be leveraged for improved competitive advantage. It is already becoming clear that as the value of data continues to grow, the current systems will not be able to handle this 'tsunami' of data and keep pace with the continuously changing environment.

\section{Analytics}

Davenport (2006) used the term analytics for the first time in an article titled 'Competing on Analytics' in Harvard Business Review. This article was followed by a book with the same title by Davenport and Harris (2007). This book is widely credited with creating awareness around analytics. A simple definition of analytics given by Davenport (2006:3) is 'the science of analysis' - a term most decision makers and managers can relate to.

Davenport and Harris (2007) list three key attributes that characterise analytics competitors. For organisations the use of basic descriptive statistics is fairly straightforward, but companies competing on analytics look well beyond basic statistical analysis. The widespread use of quantitative techniques, predictive modelling and optimisation is the most relevant of these three key attributes, according to Davenport and Harris (2007), which contributes towards more profitable operations, greater profit potential and better decision making. Many of these companies optimise their supply chains, and through that they become more resilient. Many different alternatives are simulated as well through 'what-if' analysis. The authors go further and provide a more elaborate definition of analytics as follows: 'By analytics we mean the extensive use of data, statistical and quantitative analysis, explanatory and predictive models, and fact-based management to drive decisions and actions'. Analytics, which they consider a subset of business intelligence encompassing statistical analysis, forecasting/ extrapolation, predictive modelling and optimisation, therefore provides inputs to decision making or even fully automated decisions.

The key questions addressed by analytics, as presented in Davenport et al. (2010), are reflected in Table 1.

An alternative definition of analytics is that of the Institute for Operations Research and Management Science (2014):
TABLE 1: Key questions addressed by analytics.

\begin{tabular}{|c|c|c|c|}
\hline Analytics & Past & Present & Future \\
\hline \multirow[t]{2}{*}{ Information } & What happened? & $\begin{array}{l}\text { What is happening } \\
\text { now? }\end{array}$ & What will happen? \\
\hline & (Reporting) & (Alerts) & (Extrapolation) \\
\hline \multirow[t]{2}{*}{ Insight } & $\begin{array}{l}\text { How and why did } \\
\text { it happen? }\end{array}$ & $\begin{array}{l}\text { What's the next } \\
\text { best action? }\end{array}$ & $\begin{array}{l}\text { What's the best/ } \\
\text { worst that can } \\
\text { happen? }\end{array}$ \\
\hline & $\begin{array}{l}\text { (Modelling, } \\
\text { experimental } \\
\text { design) }\end{array}$ & (Recommendation) & $\begin{array}{l}\text { (Prediction, } \\
\text { modelling, } \\
\text { simulation) }\end{array}$ \\
\hline
\end{tabular}

'the scientific process of transforming data into insight for making better decisions'. In turn Gorman (2012), presenting the views of someone with a strong quantitative background, defines analytics by three categories:

- Descriptive analytics (what happened?):

- Prepares and analyses historical data; and

- Identifies patterns from samples for reporting trends.

- Predictive analytics (what could happen):

- Predicts future probabilities and trends; and

- Finds relationships in data that may not be readily apparent with descriptive analysis.

- Prescriptive analytics (what is the best outcome given a set of circumstances):

- Evaluates and determines new ways to operate;

- Targets business objectives; and

- Balances all constraints.

In the above there are similarities with Davenport et al. (2010:81); however, Gorman (2012) clearly indicates that the focus for those with a strong quantitative background is on predictive and prescriptive analytics. Furthermore, IBM also defines Social Media Analytics, referring to the analysis of data that do not originate from within an enterprise and which are not easily interpreted as transactional data (examples would be data from Twitter, WhatsApp, etc.) and also Entity Analytics, which focuses on sorting and grouping data belonging to the same entity together (Dietrich et al. 2014:6-7).

One of the major and larger software vendors internationally, SAS, are marketing and promoting themselves as the providers of analytic solutions. Components included in the SAS Analytics suite of software are (SAS 2013):

- Predictive analytics and data mining: Build descriptive and predictive models and deploy results throughout the enterprise;

- Data visualisation: Enhance analytic effectiveness with dynamic data visualisation;

- Forecasting, econometrics and time series: Analyse and predict future outcomes based on historical patterns;

- Model management and monitoring: Streamline the process of creating, managing and deploying analytical models;

- Operations research: Leverage optimisation, project scheduling and simulation techniques to identify the actions that will produce the best results;

- Quality improvement: Identify, monitor and measure quality processes over time; 
- Statistics: Use statistical data analysis to drive fact-based decisions; and

- Text analytics: Maximise the value buried in unstructured data assets.

Computer power is increasing on a daily basis, which allows companies to address and solve problems of ever-increasing size. Through the use of this sophisticated computer technology more and more organisations are entering the era of 'big data' (see, for example, Davenport et al. 2012:22). This has prompted the realisation that (Davenport 2006:3) there is value to be obtained from the analysis of the data which can be achieved through analytics. Davenport (2006:3) provides benefits which companies can achieve through this analysis of data. Those companies using analytics seize the lead in their fields, with examples given of companies that build their very businesses on the ability to collect, analyse, and act on data. Clearly, adopting an analytics strategy will increase a company's competitiveness and therefore also its profitability. Sanford (cited in Dietrich et al. 2014:9) puts it succinctly: 'People respond to facts. Rational people will make rational decisions if you present them with the right data'.

In complex private or public sector environments those making decisions are not only dealing with huge volumes of data but also more complex issues. The ability to use business analytics in analysing big data sets enables more informed and better decision making.

\section{Supply chain analytics}

Supply chain analytics are tools and techniques that are dedicated to harnessing data from a wide range of internal and external sources to produce breakthrough insights that can help supply chains reduce costs and risks whilst improving operational agility and service quality (Deloitte \& MHI 2014:2). Davenport et al. (2010:81) give some examples of more common supply chain processes that could benefit from analytics to address the analytic questions presented in Table 1 . These examples are depicted in Table 2.

The convergence of a number of forces are steering the expansion of the possibilities for supply chain analytics. These are: (1) growing supply chain data, (2) cheaper data storage, (3) faster, and ever-increasing processing power, (4) anywhere, anytime connectivity as mobile data is available almost anywhere, (5) better tools, making analysis simpler and (6) advanced visualisation with tools and techniques to show and present huge volumes of data visually (Deloitte \& MHI 2014:4). At many companies, though, the supply chain function is currently still a step or two behind the commercial side of the business when it comes to capitalising on the power of analytics, although this is changing fast (Deloitte \& MHI 2014:2).

\section{Examples and case studies of use and implementation of analytics in supply chains}

The logistics and SCM sector is ideally placed to benefit from the technological advances as well as the parallel methodological developments through big data analysis using business analytics. Companies managing their own supply chains and those outsourcing to third-party logistics providers manage a massive flow of freight, goods and products on a daily basis whilst at the same time creating vast data sets. Millions of shipments are tracked daily from origin to destination, indicating information such as the content, weight, size, location, route, etc., of each individual shipment, across large numbers of networks (Watson et al. 2012). It is this data tracking, providing the big data, which contains potentially huge value which needs to be exploited. This analysis and exploitation is possibly still to a large extent untapped, but more and more companies are embracing these developments and experiencing the improvement of operational efficiency together with improved effectiveness as well as customer satisfaction.

In the rest of this section many examples and case studies will be highlighted, illustrating what has been achieved or showing what value can potentially be extracted through the application of analytics. The intention is not to cover all supply chain elements comprehensively, but to provide a glimpse of what can be and has been achieved in a number of areas, whilst a few actual initiatives implemented by existing companies are briefly discussed.

\section{Retail predictive analytics and vendor compliance}

Collaboration between retailers and vendors remains one of the more important aspects to enable vendors to provide the expected service. In the retailer/vendor business relationship predictive analytics cannot only analyse the entire retail supply chain process, but can also ensure vendor compliance

TABLE 2: Analytical questions - supply chain examples.

\begin{tabular}{llll}
\hline SCM examples & $\begin{array}{l}\text { Past: Product quality, Order } \\
\text { performance, Asset utilisation }\end{array}$ & $\begin{array}{l}\text { Present: Bottlenecks, Equipment } \\
\text { failures, Yield variations }\end{array}$ & $\begin{array}{l}\text { Future: Demand forecasting, Capacity } \\
\text { planning, Alternate supply }\end{array}$ \\
\hline Information & What happened? & What is happening now? \\
& (Reporting) & (Alerts) & What will happen? \\
Insight & How and why did it happen? & What's the next best action? & What's the best/worst that can happen? \\
& (Modelling, experimental design) & (Recommendation) & (Prediction, modelling, simulation) \\
SCM examples & $\begin{array}{l}\text { Process control, Quality control, } \\
\text { Bottleneck analysis }\end{array}$ & $\begin{array}{l}\text { Dynamic routing, Order continuation, } \\
\text { Preventive maintenance }\end{array}$ \\
\hline SCM, supply chain management. & & & Yield management: Product, routing, \\
Schedule optimisation
\end{tabular}

SCM, supply chain management. 
(Krupnik 2013). Retailers and vendors can benefit from this in the following ways (Krupnik 2013):

- better visibility for future orders and demand forecasts

- ability to monitor and predict low in-stock items in advance

- significantly reduce impact of late and incomplete shipments

- evaluate the combined risk of combined situations that may arise

- predict how profitable special quantity deals really are

- forecast the optimal inventory needed for promotions and what the best times are to ship the inventory

- provide retailers with the ability to suggest pricing and allocation strategies where no historical data are available.

\section{E-Commerce and market intelligence}

Chen, Chiang and Storey (2012:1165) consider business intelligence and analytics as an important area of study and research to solve data-related problems in companies. This is vividly illustrated by what web and e-commerce vendors have developed and implemented over the last few years (see introduction of section 3 and McAfee and Brynjolfsson 2012:61). Amazon, amongst many similar internet-based companies, is an excellent example of this, where they have developed analytics tools (algorithms) to analyse every 'click' on their website by thousands, possibly millions, of customers browsing for and buying products. This has enabled Amazon to, for example, not only propose customer preferences for certain products but also to manage inventories at their various distribution centres by tracking sales of different types of products and how that impacts inventories at the distribution centres. Just recently Amazon revealed its plans for predictive shipping, whereby consumer-generated information is scanned and a sophisticated analytics algorithm aims to optimise fulfilment strategies.

Therefore, instead of simply analysing sales, predictive analytics provide retailers with a view into the future and an opportunity to identify patterns that lead to effective and highly personalised customer engagement strategies. Where descriptive analytics measures what has already happened, predictive analytics applies statistical modelling and data mining to study recent and historical data, thus allowing for more accurate forecasting.

Loyalty cards are another example of the use of big data and analytics that has major applications for product ranges, inventories, etc., as well as market intelligence. For each item bought at a retail store using loyalty cards, the store can through proper analysis of the point-of-sale data determine exactly what items are bought, what the preferences of loyalty card holders are, the size of purchases, etc., and what the implications are for different products, product inventory for different times of the month/year (introducing seasonality), order quantities and when to order, which stores are more profitable, and which stores are solicited more often, leading to better location decisions, etc. Marketing initiatives can be guided significantly by analysis of the big data obtained in this manner.

\section{Visibility}

Visibility is an essential necessity of tracking products in an end-to-end manner throughout the supply chain. Gartner Research (2013) recently reported that virtually no company is able to, or will be able to, provide end-to-end supply chain visibility in the near future. Through advanced analytics, both predictive and prescriptive, it is becoming possible to provide real-time visibility across the supply chain and in addition to improve forecasting, demand planning, sourcing, replenishment, production, transportation, and distribution processes (One Network Enterprises 2014:2). With this improved (or big) visibility companies will inter alia be able to model supply chain data with higher precision, alter decisions in real time and utilise predictive and prescriptive analytics to solve problems before they occur.

\section{IBM - applying analytics to the supply chain}

As an international company with a presence in 170 countries, IBM recognised the value of analytics and embraced it in optimising their supply chains (Dietrich et al. 2014). Numerous solutions have been deployed; four examples are discussed briefly to illustrate the range of problems solved using a variety of analytics tools:

- Quality early-warning system: This system detects and prioritises quality problems much sooner than traditional statistical process control. This is a big data analytics solution that is deployed upstream at suppliers, in IBM's operations and with products in the field. Using huge amounts of data sourced from across the supply chain and analysing these it was possible to reduce rework, increase productivity, ensure higher quality and increase customer satisfaction. This led to significant cost savings.

- IBM buy analysis tool: With many business partners ensuring the correct inventory levels is tough. This tool not only provides supply and demand visibility, it ensures better distribution channel management and well as making sure the right product is delivered to meet customer demand, whilst at the same time minimising inventory levels.

- Account receivable - next best action: With this tool, using advanced analytics, the resources required to collect revenues are optimised.

- Supply chain social listening: A very innovative way to use social media to monitor social channels to provide valuable and timely data on events (e.g. disasters) which may disrupt the supply chain. Information on products can also be obtained in this way. There are many other uses for this already as well as potential applications.

IBM demonstrates the use of mainly predictive and prescriptive analytics through real examples implemented over the last number of years. 


\section{DHL: Big data in logistics}

As one of the leading global parcel courier service companies, DHL, operating in a dynamic and fast-changing environment, strives to continuously innovate, in this way developing new strategies to remain competitive (DHL 2013a, 2013b). Not only is the company continuously scanning the horizon for megatrends in the global environment, as well as considering new emerging technologies, but these are them used to develop new services and business models. From a big data perspective they identified two major driving forces (DHL 2013b:1):

- How can DHL move from a 'deep well of data' to deep exploitation?

- How this can be used to improve operational efficiency and customer service leading to new business models?

Using advanced IT technologies and analytics enables DHL to analyse vast amounts of data much faster. A number of areas where DHL have implemented these new innovations and models include the following (DHL 2013b: 18-27):

- Last-mile optimisation: The last mile is always one of the challenges to deliver goods fast and cost-effectively. The last-mile efficiency is improved by processing a massive stream of data to attain:

- Real-time route optimisation: Rapid processing of real-time information on the last mile supports the goal of saving time in the delivery process.

- Crowd-based pick-up and delivery: Using commuters, students or taxi drivers to make last-mile deliveries on the routes they are travelling anyway.

- Predictive network and capacity planning: Avoiding excess or capacity shortages through:

- Strategic network planning: Adapting the distribution network according to anticipated future demand.

- Operational capacity planning: Using real-time information about shipments. In this way the allocation of resources required for the next 48 hours can be predicted.

- Customer value management: Using data from distribution networks can be used to limit customer attrition and understand customer demand through:

- Customer loyalty management: To retain customers' big data analysis allows a comprehensive assessment of customer satisfaction by merging multiple extensive data sources.

- Continuous service improvement and product innovation: Here customer feedback is used for continuous improvement of service quality and product innovation.

- Supply chain risk management: Rapid analysis of various information streams can assist to forecast events and take measures to minimise the associated potential risk, This includes:

- Risk evaluation and resilience planning: Continuous monitoring of supply chains to detect performance deviations, etc.
- B2B demand and supply chain forecast: Using insights from the flow of goods and millions of daily shipments, demand and supply chain requirements can be forecasted:

- Market intelligence for small and medium-sized companies: By analysing shipment records a market research service can be provided to small and medium-sized enterprises.

- Financial demand and supply chain analytics: Data collected from global distribution networks provide insight into growth perspectives, etc.

- Real-time local intelligence: Pick-up and delivery shipment data analysis is a huge source of intelligence:

- Address verification: Verification of customer's address, a big requirement for online commerce.

- Environmental intelligence: Using different sensors on delivery vehicles can produce environmental statistics such as city expansion and pollution.

What is described above is very innovative, but also forwardthinking, plus the realisation of what the combination of big data and advanced analytics can achieve. To remain competitive in a very dynamic and cut-throat environment DHL believes it needs to develop its future strategies utilising big data with the appropriate analytic tools and methodologies.

\section{End-to-End Analytics}

End-to-End Analytics, a supply chain analytics company in the United States of America, offers clients analysis of big data, data visualisation; open and full interaction with clients; as well as better insight and understanding of issues (Kessinger \& Pieper 2013:20-22). Examples of their work include:

- Forecasting reality check: Tens of thousands of productlevel forecasts make manual review impossible and unfeasible. An automatic system calculates the probability of a forecast being realised using historical demand patterns; through this the most 'suspicious' forecasts are detected, improving overall forecast error immediately by $5 \%-10 \%$.

- Pricing: Price-related issues include price setting, price execution and price optimisation. An example is mentioned where complex segmentation logic using 11 different variables to improve price setting was developed, and this resulted in significantly higher margins.

- Supply chain planning: With clients they have jointly developed process improvements spanning from longrange volume planning to planning of weekly part schedules for suppliers, distribution of vehicles to dealers and optimal inventory strategies for accessory wheels for an automotive manufacturing company.

\section{Conclusion}

Observing what is happening in the world, given the developments in information and mobile technology, there is no doubt that we find ourselves in the era of 'big data'. In 
addition, advanced computer power allows for the analysis of data in a much more focused, faster and bigger way than ever before. Organisations need to understand forces in their marketplace better and respond faster to changes in their environment in order to remain competitive. The proper use of any tools and methodology to assist in this is essential.

This article endeavours to provide an overview of new developments that show how companies in many sectors are making efforts to move from 'gut-feel' decision making to accurate, data-driven insight to achieve effective business decision making. Supply chain managers in the supply chain and logistics environment, in general, need to embrace these developments to remain efficient, effect and competitive.

Anticipating sales volumes, customer preferences for products and optimising work schedules are a few examples where proper analysis of big data has the power to help business succeed. Further extensive examples are covered in the article. It is critical that SCM and logistics decision makers take note of the fact that as data and analytics transform organisations, and the landscape within which they operate, it inevitably puts additional new demands on management. For any organisation to achieve what has been outlined in this paper it is necessary to take a whole range of steps and actions. These include aspects such as, inter alia, working across functional areas, data capturing, ensuring data integrity, data management, tools and techniques to perform the necessary analytics analysis, and the human resources capability required to achieve all of this.

Although all of these are of great importance, there has been no effort to address any of these in this article. Currently the leadership capacity in many organisations is still lacking and undermining efforts to respond fast and appropriately to these changes to create the appropriate management structures and roles (Brown, Court \& Willmott 2013:78). However, supply chain managers should not be caught unawares, as changes are taking place and are inevitable.

The objective of this article was to expose supply chain managers to the growing importance of two trends that have the potential of changing and impacting the SCM industry in a big way. 'Big data' was defined and discussed, whilst analytics was outlined as it is currently defined and understood. A number of applications are discussed where 'big data' with analytics have been successfully implemented showing the benefits that can be derived through the adoption and drive towards data-driven decisions.

Finally, change is never easy in any environment. However, this article conveys in a concise manner the changes taking place in a very dynamic world. It is shown through a number of examples how these have impacted supply chains where the changes have been embraced. Big data is a reality and using analytics to extract maximum value from the data has the potential to make a huge impact. Supply chain managers need to take note of the value of data-driven decisions. Only in this way will it be possible to continue to enhance the performance of supply chains, and through this for organisations to remain competitive.

\section{Acknowledgements Competing interests}

The author declares that he has no financial or personal relationships which may have inappropriately influenced him in writing this article.

\section{References}

Baesens, A., 2014, Analytics in a big data world: The essential guide to data science and its applications, John Wiley \& Sons, Hoboken, New Jersey.

Brown, B., Court, D. \& Willmott, P., 2013, 'Mobilizing your C-suite for big-data analytics', McKinsey Quarterly 4, 76-87.

Chen, H., Chiang, R.H.L. \& Storey, V.C., 2012, 'Business intelligence and analytics: From big data to big impact', MIS Quarterly 36(4), 1165-1188.

Christopher, M., 1998, Logistics and supply chain management, 2nd edn., Pearson Education, London.

Coles, P., Cox, T., Mackey, C. \& Richardson, S., 2006, The toxic terabyte: How dato dumping is threatening business, IBM Global Technology Services, London, pp. 1-11.

Cooke, J.A., 2013, 'Three trends to watch in 2013, Perspective', Supply Chain Quarterly 1,11 .

Court, D., 2015, 'Getting big impact from big data', McKinsey Quarterly 1, 52-60.

Davenport, T.H., 2006, 'Competing on analytics', Harvard Business Review Jan., 2-10.

Davenport, T.H. \& Harris, J.G., 2007, Competing on analytics - the new science of winning, Harvard Business School Publishing Corporation, Boston, Massachusetts.

Davenport, T.H., Barth, P. \& Bean, R., 2012, 'How "Big Data" is different', MIT Sloan Management Review, Fall, 22-24.

Davenport, T.H., Harris, J.G. \& Morison, R., 2010, Analytics at work-smarter decisions, better results, Harvard Business Press, Boston, Massachusetts.

Deloitte \& MHI, 2014, The 2014 MHI Annual Industry Report - Innovations that drive supply chains, MHI, Charlotte, North Carolina, USA.

DHL, 2013a, Logistics trend radar-delivering insight today. Creating value tomorrow!, DHL Customer Solutions \& Innovation, Troisdorf, Germany.

DHL, 2013b, Big Data in logistics - a DHL perspective on how to move beyond the hype, DHL Customer Solutions \& Innovation, Troisdorf, Germany.

Dietrich, B., Plachy, E.C. \& Norton, M.F., 2014, Analytics across the enterprise: How IBM realizes business value from big data and analytics, IBM Press Books, Boston, Massachusetts.

Eccles, H.E., 1954, 'Logistics - What is it?', Naval Research Logistics Quarterly, 1(1), 5-15. http://dx.doi.org/10.1002/nav.3800010104

Gartner Research, 2012, Predicts 2013: Collaboration, cloud and evolving strategies will drive global logistics, viewed 11 November 2014, from https://www.gartner com/doc/2243416/predicts--collaboration-cloud-evolving

Gorman, M.E., 2012, Analytics, viewed 11 September 2012, from http://www.informs. org/Participate-In-a-Community/Societies-and-Sections/Analytics/

Institute for Operations Research and Management Science, 2014, What is analytics? viewed 22 October 2014, from https://www.informs.org/About-INFORMS/Whatis-Analytics

Ittmann, H.W., 2013, Operational research and business analytics: Different but the same?, International Symposium on Operational Research and Applications (ISORAP) Proceedings (available on CD), Marrakech, Morocco, May 7-8, 2013.

Kessinger, C. \& Pieper, H., 2013, 'End-to-End Analytics - Supply chain analytics company offers clients analysis, visualization, interaction and insight', OR/MS Today Aug., 20-22.

Krupnik, Y., 2013, '7 ways predictive analytics helps retailers manage suppliers', Predictive Analytics Times, 26 August 2013, viewed 07 November 2014, from http://www.predictiveanalyticsworld.com/patimes/7-ways-predictive-analyticshelps-retailers-manage-suppliers/

Lewis, M., 2003, Moneyball: The art of winning an unfair game, W.W. Norton \& Company, New York.

McAfee, A. \& Brynjolfsson, E., 2012, 'Big data: The management revolution', Harvard Business Review 90(10), 61-68.

McKinnon, A., Cullinane, S., Browne, M. \& Whiteing, A., 2010, Green logistics improving the environmental sustainability of logistics, Kogan Page, London. 
One Network Enterprises, 2014, Turning 'big data' into 'big visibility', White Paper, One Network Enterprises, viewed 11 November 2014, from http://go.onenetwork. com/big-data-big-visibility

Richey, G., Morgan, T., Lindsay, K. \& Yoon, A., 2014, Big data, CSCMP Hot topics, viewed 21 October 2014, from https://cscmp.org/member-benefits/hottopics

Samuelson, D.A., 2009, 'Change we can blog in: Obama's use of on-line social networking to help him govern', OR/MS Today Feb., 29-31.

Samuelson, D.A., 2013, 'Analytics: Key to Obama's victory', OR/MS Today Feb., 20-24. Samuelson, D.A., 2014, 'Analytics penetrates deeper into politics', OR/MS Today Oct., 26-29.

SAS, 2012, Big data meets big data analytics, viewed 21 October 2014, from http:// www.sas.com/content/dam/SAS/en_us/doc/whitepaper1/big-data-meets-bigdata-analytics-105777.pdf

SAS, 2013, Advanced analytics, viewed 01 February 2013, from http://www.sas.com/ technologies/analytics/
Sathi, A., 2012, Big data analytics: Disruptive technologies for changing the game, MC Press Online, LLC, Boise, ID 83703, USA

Siegel, E., 2013, Predictive analytics: The power to predict who will click, buy, lie or die, John Wiley \& Sons Inc., Hoboken, New Jersey.

Stock, J.R., 2013, 'Supply chain management: A look back, a look ahead', Supply Chain Quarterly 2, 22-26.

Svilar, M., Chakraborty, A. \& Kanioura, A., 2013, 'Big data analytics in marketing', OR/ MS Today Oct., 22-25.

Tomasini, R. \& Van Wassenhove, L., 2009, Humanitarian Logistics, Palgrave MacMillan, Hampshire.

Waller, M.A. \& Fawcett, S.E., 2013, 'Data science, predictive analytics, and big data: a revolution that will transform supply chain design and management', Journal of Business Logistics 34(2), 77-84.

Watson, M., Lewis, S., Cacioppi, P. \& Jayaraman, J., Supply chain network design applying optimization and analytics to the global supply chain, FT Press, Upper Saddle River, New Jersey. 